\title{
Investigation on the formation of $\mathrm{Cu}-\mathrm{Fe}$ nano crystalline super-saturated solid solution developed by mechanical alloying
}

\author{
M. Mojtahedi a,*, M. Goodarzi ${ }^{\text {a }}$, M.R. Aboutalebi ${ }^{\text {a }}$, M. Ghaffari ${ }^{\text {b }}$, V. Soleimanian ${ }^{\text {c }}$ \\ a School of Materials Science and Engineering, Iran University of Science and Technology, Narmak, Tehran 16846-13114, Iran \\ ${ }^{\mathrm{b}}$ Department of Electrical and Electronics Engineering, UNAM-Institute of Materials Science and Nanotechnology, Bilkent University, Ankara 06800, Turkey \\ ${ }^{\mathrm{c}}$ Department of Physics, Faculty of Science, Shahrekord University, P.O. Box 115, Shahrekord, Iran
}

\section{A R T I C L E I N F O}

\section{Article history:}

Received 7 September 2012

Received in revised form 19 October 2012

Accepted 22 October 2012

Available online 1 November 2012

\section{Keywords:}

Mechanical alloying

Solid solubility extension

XDA

Rietveld refinement

HRTEM

HAADF

\begin{abstract}
A B S T R A C T
In this study, the formation of super saturated solid solution in the binary $\mathrm{Cu}-\mathrm{Fe}$ system was investigated. Three powder blends with 30, 50 and $70 \mathrm{wt} . \%$ of Fe were milled for different times to $96 \mathrm{~h}$. The variations of lattice parameter and inter-planar spacing were calculated and analyzed using X-ray diffraction analysis (XDA). The anisotropy of lattice deformation in the FCC phase was studied and the obtained results were compared to milled pure $\mathrm{Cu}$ powder. Furthermore, crystallite size was calculated using Scherer formula in comparison with Rietveld full profile refinement method. Considering the previous studies about the formation of non-equilibrium FCC and BCC phases, the phase evolution has been discussed and the proportion of each phase was calculated using Rietveld refinement method. Supplementary studies on the evolution of microstructure and formation of solid solution were carried out using high resolution transmission electron microscopy (HRTEM). Finally, high angle annular dark field (HAADF) imaging was utilized to find out the level of homogeneity in the resulting phases. While true alloying takes place in each phase, the final structure consists of both FCC and BCC nano-crystallites.
\end{abstract}

(c) 2012 Elsevier B.V. All rights reserved.

\section{Introduction}

Mechanical alloying has been an attractive method for synthesis of super-saturated metallic solutions. Copper base alloys have been the subject of numerous studies in this field. Several important engineering metals have limited solubility in copper, such as Fe, $\mathrm{Cr}, \mathrm{Co}, \mathrm{Mo}, \mathrm{Mg}$, V and Ti. Production of super-saturated alloys, amorphous phases or intermetallic compounds in binary systems of $\mathrm{Cu}$ with BCC metals like Nb [1-2], Cr [3,4], Li [5], Mo [6,7], V [8] and $\mathrm{W}[9,10]$, have been widely investigated using mechanical alloying. There are also studies on binary systems of Cu with FCC metals such as $\mathrm{Al}$ [11], HCP metals like Co [12,13] and $\mathrm{Zn} \mathrm{[14],} \mathrm{in} \mathrm{addition} \mathrm{to}$ non-metallic elements like carbon [15]. Studies on systems with three or more constituents have been conducted as well [16-21].

Relatively more studies have been focused on the $\mathrm{Cu}-\mathrm{Fe}$ alloying system. Some researches just considered the equiatomic composition [22-26], while others scrutinized wider ranges [16,27-35]. Moreover, explorations have been done on the copper rich [36] or the iron rich alloys [37]. The solubility limits can change significantly in the mechanically alloyed systems. The crystal structures obtained in various compositions by former researchers are summarized in Fig. 1.

\footnotetext{
* Corresponding author. Tel.: +98 21 77240500; fax: +98 2177240599

E-mail address: m.mojtahedi@gmail.com (M. Mojtahedi).
}

To the best of the author's knowledge, the majority of research on the formation of this non-equilibrium solution utilized X-ray diffraction method, but the analysis of XRD patterns are conducted using different methods which can cause a difference in the final results. Not many used just XRD $[26,40]$, but more preferred to make use of Mossbauer spectroscopy beside XRD to study the homogeneity and atomic level mixing of elements [16,25,41-43]. Transmission electron microscopy is also a powerful technique for inspection of microstructural transformation which has been used alongside XRD for this system [28,32,33,37]. Furthermore, neutron diffraction analysis was also used to study the mechanically alloyed $\mathrm{Cu}-\mathrm{Fe}$ admixtures [42,44].

In spite of the extensive scientific study, there are different viewpoints in the literature about whether a single phase solid solution with anatomically homogeneous structure is obtained or not. Therefore, the aim of this work is to study the micro-structural changes and phase formation in the $\mathrm{Cu}-\mathrm{Fe}$ system with the aid of satisfactory XRD analysis methods and high resolution TEM in addition to high angle annular dark field scanning tunneling electron microscopy (HAADF STEM) to obtain reassuring proof about the XDA results.

\section{Materials and methods}

The elemental $\mathrm{Cu}$ and Fe powders were mixed before milling to achieve equiatomic, $\mathrm{Cu}$ rich and Fe rich compositions. The milling is conducted under argon atmosphere using a planetary ball mill with ball to powder ratio of 20:1 and 


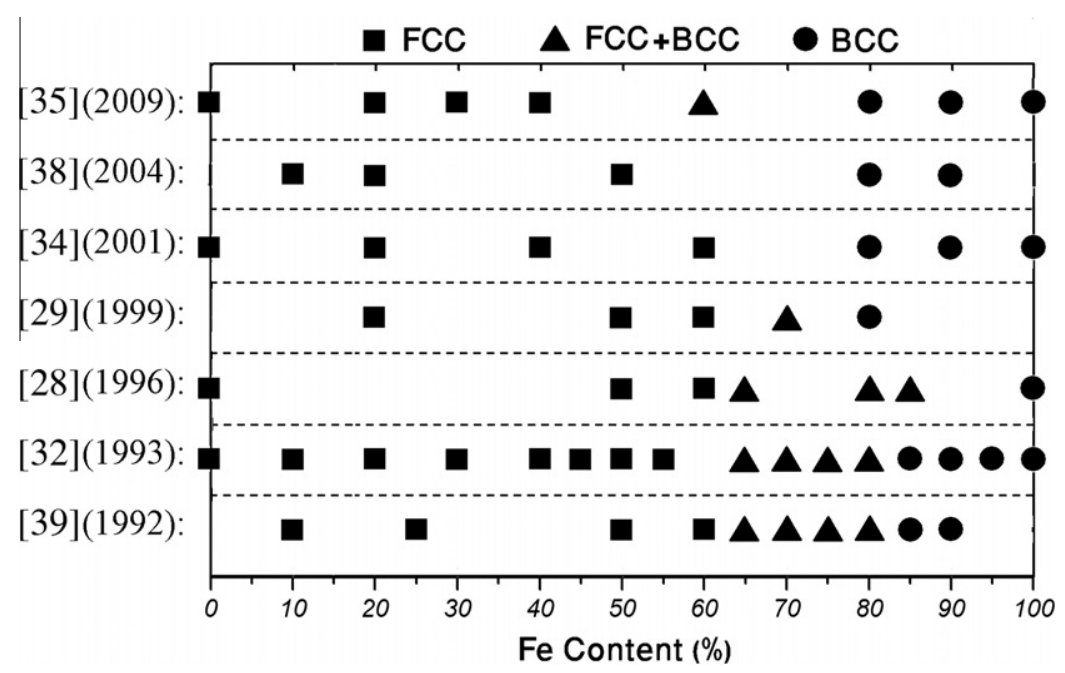

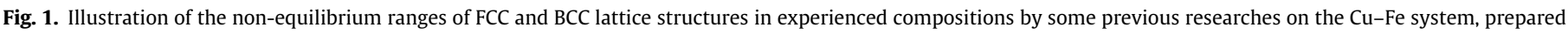
by mechanical alloying. (see above mentioned references for further information.)

Table 1

Different milling conditions beside lattice parameter and Crystallite size (Rietveld method) towards the directions of X-ray diffraction from FCC and BCC structures.

\begin{tabular}{|c|c|c|c|c|c|c|c|c|c|c|c|c|c|c|c|}
\hline \multirow[t]{2}{*}{$\begin{array}{l}\text { Sample } \\
\text { code }\end{array}$} & \multicolumn{2}{|c|}{ Composition } & \multirow[t]{2}{*}{$\begin{array}{l}\text { Milling } \\
\text { time (h) }\end{array}$} & \multirow{2}{*}{$\begin{array}{l}\text { FCC Lattice } \\
\text { parameter } \\
(\AA) \\
(\AA)\end{array}$} & \multirow[t]{2}{*}{$\begin{array}{l}\text { Average FCC } \\
\text { crystallite size } \\
(\mathrm{nm})\end{array}$} & \multicolumn{5}{|c|}{ FCC crystallite size $(\AA ̊)$} & \multirow{2}{*}{$\begin{array}{l}\text { BCC lattice } \\
\text { parameter } \\
(\hat{\prime})\end{array}$} & \multirow[t]{2}{*}{$\begin{array}{l}\text { Average BCC } \\
\text { crystallite size } \\
(\mathrm{nm})\end{array}$} & \multicolumn{3}{|c|}{$\begin{array}{l}\text { BCC crystallite } \\
\text { size }(\AA \hat{)})\end{array}$} \\
\hline & $\begin{array}{l}\mathrm{Cu} \\
\text { (wt.\%) }\end{array}$ & $\begin{array}{l}\mathrm{Fe} \\
\text { (wt.\%) }\end{array}$ & & & & 111 & 200 & 220 & 311 & 222 & & & 110 & 200 & 211 \\
\hline $0-48$ & 100 & 0 & 48 & 3.6181 & 10.74 & 135 & 76 & 95 & 96 & 135 & - & - & - & - & - \\
\hline $3-6$ & 70 & 30 & 6 & 3.6200 & 11.74 & 142 & 90 & 105 & 108 & 142 & 2.8693 & 6.13 & 61 & 58 & 65 \\
\hline $3-12$ & 70 & 30 & 12 & 3.6266 & 10.64 & 129 & 82 & 94 & 98 & 129 & 2.8714 & 8.47 & 75 & 86 & 93 \\
\hline $3-24$ & 70 & 30 & 24 & 3.6338 & 9.34 & 116 & 69 & 81 & 85 & 116 & 2.8743 & 4.23 & 49 & 40 & 38 \\
\hline $3-48$ & 70 & 30 & 48 & 3.6468 & 7.78 & 102 & 55 & 61 & 69 & 102 & - & - & - & - & - \\
\hline $3-96$ & 70 & 30 & 96 & 3.6466 & 6.26 & 79 & 47 & 51 & 57 & 79 & - & - & - & - & - \\
\hline $5-6$ & 50 & 50 & 6 & 3.6211 & 9.08 & 112 & 64 & 97 & 69 & 112 & 2.8703 & 4.8 & 65 & 35 & 44 \\
\hline $5-12$ & 50 & 50 & 12 & 3.6290 & 6.74 & 83 & 48 & 63 & 60 & 83 & 2.8724 & 4.67 & 60 & 34 & 46 \\
\hline $5-24$ & 50 & 50 & 24 & 3.6572 & 5.28 & 69 & 38 & 42 & 47 & 68 & 2.8759 & 4.93 & 47 & 36 & 65 \\
\hline $5-48$ & 50 & 50 & 48 & 3.6667 & 5 & 67 & 33 & 40 & 43 & 67 & - & - & - & - & - \\
\hline $5-96$ & 50 & 50 & 96 & 3.6609 & 5.26 & 69 & 38 & 41 & 46 & 69 & - & - & - & - & - \\
\hline $7-6$ & 30 & 70 & 6 & 3.6286 & 7.38 & 91 & 52 & 69 & 66 & 91 & 2.8709 & 5.83 & 78 & 44 & 53 \\
\hline $7-12$ & 30 & 70 & 12 & 3.6318 & 4.22 & 70 & 39 & 41 & 39 & 69 & 2.8719 & 6.53 & 68 & 57 & 71 \\
\hline $7-24$ & 30 & 70 & 24 & 3.6738 & 3.6 & 56 & 20 & 23 & 25 & 56 & 2.8746 & 2.03 & 22 & 25 & 14 \\
\hline $7-48$ & 30 & 70 & 48 & 3.6792 & 5.16 & 48 & 56 & 51 & 53 & 50 & - & - & - & - & - \\
\hline $7-96$ & 30 & 70 & 96 & 3.6645 & 4.38 & 61 & 29 & 29 & 39 & 61 & - & - & - & - & - \\
\hline
\end{tabular}

rotation speed of $370 \mathrm{rpm}$. After each $45 \mathrm{~min}$ of milling, the operation was stopped for $15 \mathrm{~min}$ to avoid rising temperature. One weight percentage of Stearic acid was used as lubricant to prevent too much adhesion of the milled powder to the vial and balls. The applied compositions and milling times are shown in (Table 1).

The resultant powders were analyzed using XRD technique. The level of background is relatively high when specimens containing iron are exposed to copper $\mathrm{K}_{\alpha}$ radiation; therefore, an instrument with Cobalt $\mathrm{K}_{\alpha}$ radiation $(1.78901 \AA$ ) is used (PHILIPS-Xpert) to provide a better separation of the shape of short peaks from the background data. The $2 \theta$ step was set at $0.02^{\circ}$ and the counting time per step was $4 \mathrm{~s}$. The instrumental broadening was calculated using Caglioti equation [45]:

$\mathrm{FWHM}^{2}=U \tan ^{2}(\theta)+V \tan (\theta)+W$

In which $\theta$ is diffraction angle, FWHM is full width at half maximum of any peak and $U, V$ and $W$ are indices which are determined using a standard specimen with large grains and no internal strain. Therefore, a pure alumina sample was prepared as standard specimen in this work.

The X-ray profiles were studied using Scherer equation [46] in addition to Rietveld full profile analysis method [47] to determine crystallographic characteristics of the milled powder. After fitting the Caglioti equation and calculation of instrumental broadening for diffraction angels of the $\mathrm{Cu}-\mathrm{Fe}$ powder, the true broadening data for the Scherer equation was extracted by the subtraction of the square of two broadenings [48]. The relative amount of the FCC and BCC phases in each sample was determined by comparing related peaks using Rietveld method and Fullprof software. Fig. 2 shows the profiles obtained from experiment and the profiles calculated using Rietveld refinement, for samples $0-48,3-6,5-12$ and 7-12. As is seen, a fairly good agreement between the experimental and calculated profiles can be observed.

High resolution TEM imaging was conducted to investigate the formation of milled structure at the scale of nano crystallites, using a Tecnai G2 F30 instrument with $300 \mathrm{kV}$. The powder was dispersed in acetone by ultrasonic vibration for $2 \mathrm{~min}$. Then two drops were instilled on a TEM carbon grid. HAADF technique was also performed in order to evaluate the homogeneity of the alloying elements in the resultant powders.

\section{Results and discussion}

\subsection{X-ray diffraction analysis (XDA)}

\subsubsection{Phase evolution}

X-ray profiles of the powder mixture samples with 70 wt.\% Fe which are mechanically alloyed for different times are compared in Fig. 3. As can be seen, by increment of the milling time, the $\mathrm{Cu}$ and Fe peaks shift to lower angles, which is an indication of an increase in the distance between lattice planes. The intensities of all peaks are reduced as a result of more milling time, up to $48 \mathrm{~h}$. After $48 \mathrm{~h}$ of mechanical alloying, it seems that the peaks of the 

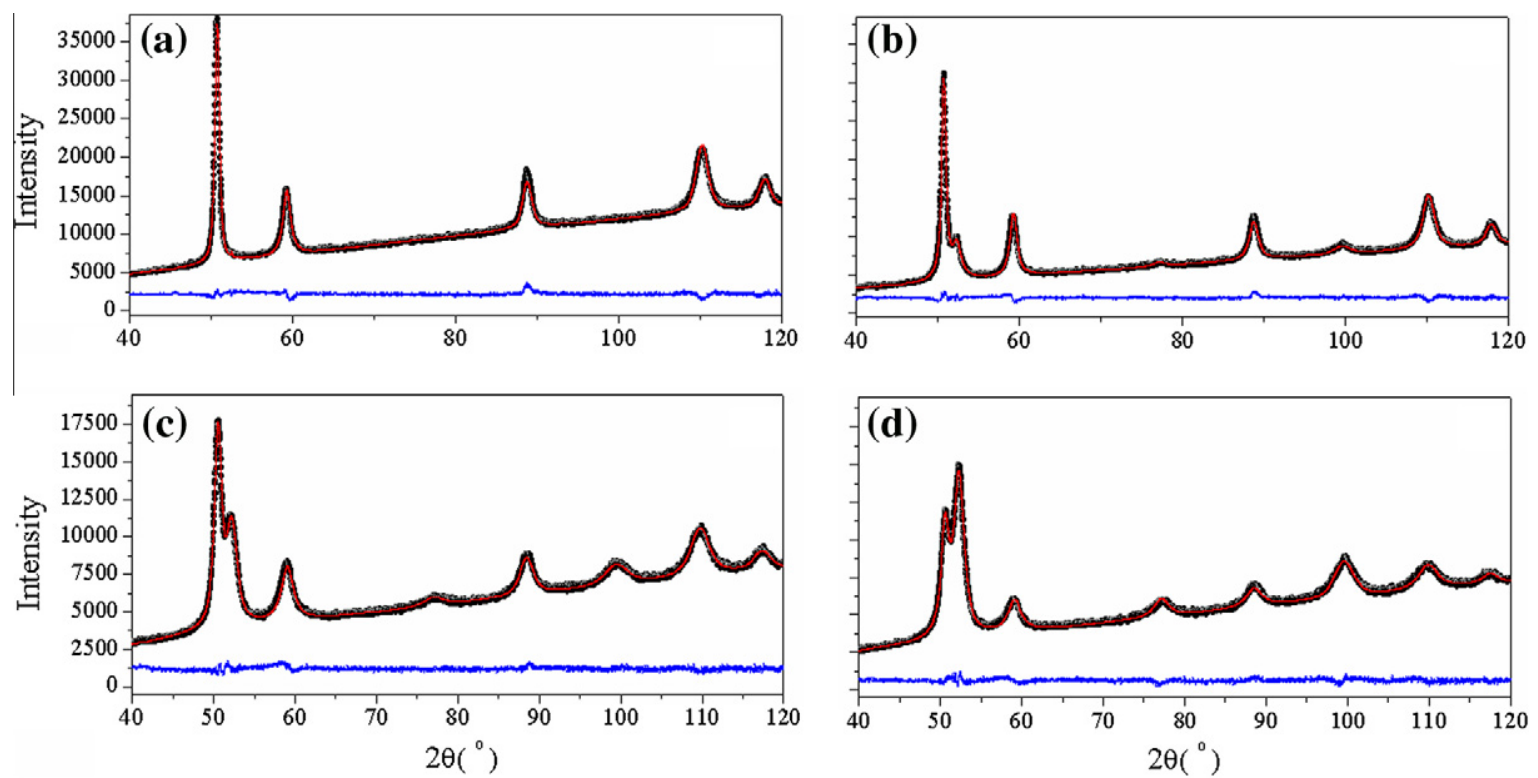

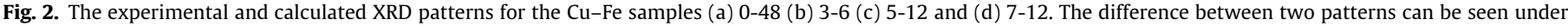
each profile.

BCC phase disappear and a completely FCC solid solution is formed. However, the asymmetric shape of the right tail of the $\mathrm{Cu}(111)$ peak points out an overlap with the $\mathrm{Fe}(110)$ peak. If the time of exposing the sample to X-ray radiation is not sufficient or the noise and background are high, the small peaks may be indistinguishable, while the diffraction peak of $\mathrm{Fe}(110)$ is distinguishable as a shoulder to the $\mathrm{Cu}(111)$ peak, in all of the XRD profiles. By further milling up to $96 \mathrm{~h}$, the intensity of the $\mathrm{Fe}(110)$ peak continues the trend of reduction while the FCC peaks show a slight amplification.

Extension of solubility limit to more than $50 \%$ by mechanical alloying, have been seen in few metallic binary systems. $60 \%$ of $\mathrm{Al}$ in $\mathrm{Ti}$ [49] and $86 \%$ of $\mathrm{Al}$ in $\mathrm{W}$ [50] can be addressed as examples. The $\mathrm{Fe}-\mathrm{Cu}$ system is somehow an unique case. The difference in

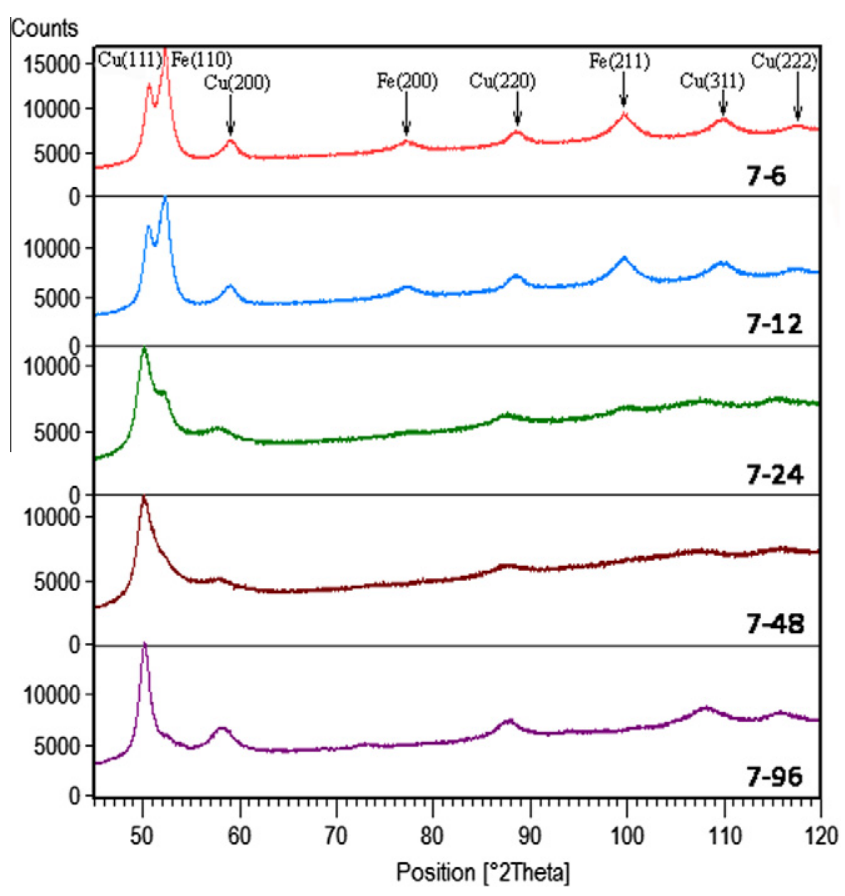

Fig. 3. The effect of milling time on XRD pattern of samples with $70 \% \mathrm{Fe}$. atomic radius is just $1.5 \%$ and the electro-negativities are close together (1.9 for $\mathrm{Cu}$ and 1.8 for $\mathrm{Fe}$ ) but the equilibrium solubility is near zero at room temperature. On the other hand, mechanical alloying is the only non-equilibrium technique that can extend the solubility limit of $\mathrm{Fe}$ in $\mathrm{Cu}$ to more than equiatomic composition. By comparing the free energy curves of FCC and BCC phase in the $\mathrm{Cu}-\mathrm{Fe}$ system, it is claimed that addition of enthalpy of defects to the free energy curves, shift the crossing of FCC and BCC plots towards Fe reach concentrations [43]. However, our results show that the solubility limit of $\mathrm{Fe}$ in $\mathrm{Cu}$ is lower than the amounts illustrated in Fig. 1, which are all more than 50\%. It is in agreement with another work which is reported the remaining of Fe peaks in a powder with $40 \%$ Fe content, using high intensity XRD peaks [51].

As can be seen in Table 1 and Fig. 4, by an increase in the Fe content of the samples an extra increment in lattice parameter is obtained. It should be noticed that the rate of increment of lattice parameter before reaching the steady state level, can be different in publications. This is related to the milling parameters and energy transfer in the vial.

The difference between the amounts of increment of the lattice parameter in the sample of pure copper milled for $48 \mathrm{~h} \mathrm{(0-48)} \mathrm{com-}$ pared with samples 3-48, 5-48 and 7-48, is significant. The higher order of changes proves the entrance of alloying element in the lattice of the FCC phase. This trend is in agreement with previous studies [29-30,33], while the amount of increase in the present conditions of mechanical alloying is greater. In the specimens with $70 \mathrm{wt} . \%$ iron, by increasing the milling time the FCC phase is still dominant and the peaks show a relatively severe displacement.

The changes in the lattice parameter of the FCC phase do not show an uniform behavior in different series of specimens. As illustrated in Fig. 5, in series 5 and 7 there is a major increase in lattice parameter between 12 and $24 \mathrm{~h}$ of milling. This predicates that alloying mainly takes place in this period of time. But in series 3 , the changes are more uniform while the increase in lattice constant between 6 and $12 \mathrm{~h}$ is slightly higher, which can confirm that more Fe content postpones the trend of the alloying process.

In case of mechanical alloying of ductile metallic powders, it is not unusual to see a slight decrease in the lattice strain, after the sharp initial increase. The smaller the crystallite size, the generation of new dislocations is harder [52]. When the crystallite size 


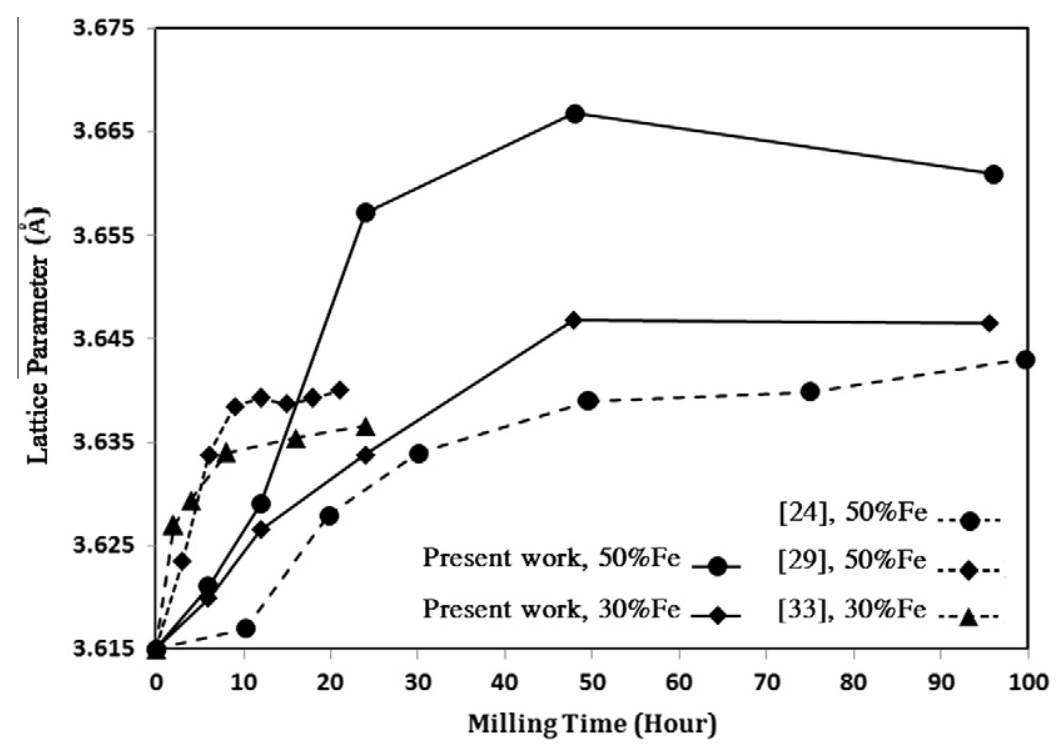

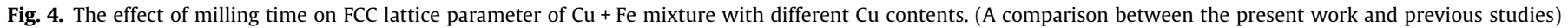

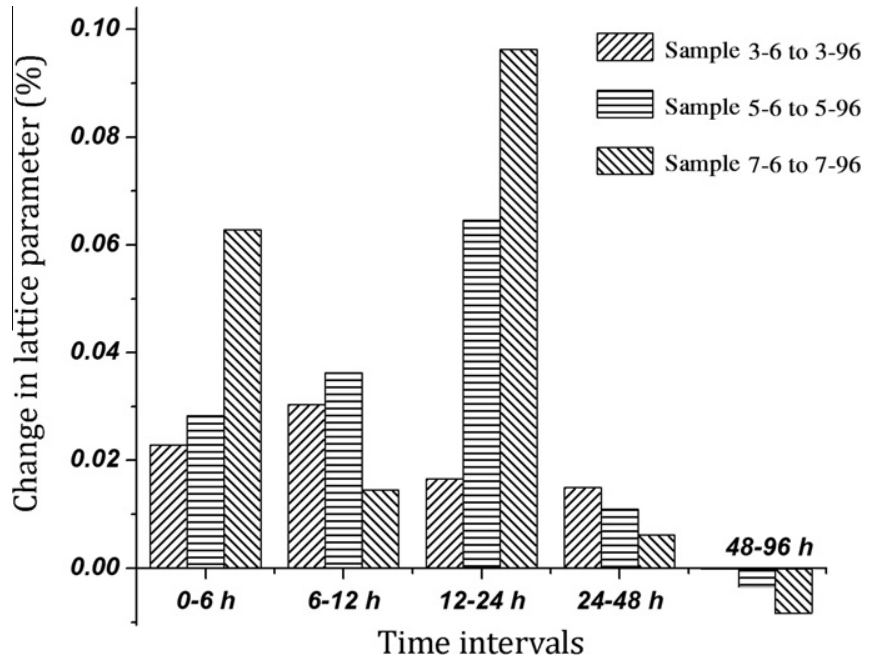

Fig. 5. Variation of the lattice parameter of the FCC phase per hour of milling time.

and dislocation density reach a saturation value, the existing dislocations rearrange and some may be annihilated. Therefore the lattice strain decreases, the XRD peaks become sharper and the peak position may change in reverse order. This trend can be seen in samples with $50 \%$ Fe content. But in case of $70 \% \mathrm{Fe}$, we see a relatively severe change in the sharpness of FCC peaks. The shape of the XRD profile of the sample 7-48, implies that an amorphous phase may be formed. Therefore, the change of profile shape in the 48-96 h interval could be due to re-crystallization of amorphous regions in the powder containing $70 \%$ of $\mathrm{Fe}$.

There is some disagreement over complete and atomic level dissolution in the mechanically alloyed $\mathrm{Cu}-\mathrm{Fe}$ powder in the literature. According to the XRD peaks of $\mathrm{Cu}$ and $\mathrm{Fe}$, it is stated that the output of mechanical alloying is a single FCC or BCC phase in the related compositions $[25,27,32,33]$. However, there are some difficulties in X-ray diffraction analysis of such powders. The presence of highly deformed crystallites in the size of a few nano meters makes the peaks short and broadened, and sometimes hard to identify. Moreover, by the decrease in the crystallite size, the minimum necessary amount of a phase to be detected by XRD increases [53]. These should be added to the fact that there can be a very slight difference between a solid solution and a nano structured mixture.

Therefore, previous researchers have implemented other X-ray diffraction analysis methods. By the aid of extended X-ray absorption fine structure (EXAFS) technique, it has been stated that $\mathrm{Cu}$ and Fe make an atomic level solution [22]. Although it is mentioned that this is not a general conclusion, the usage of EXAFS in the analysis of $\mathrm{Ag}-\mathrm{Fe}$ powder mixture showed that an atomic solution did not form in mechanical alloying of this system [54], which also has a positive heath of mixing. On the other hand, by usage of EXAFS it is reported [34] that in mixtures with more than 60\% copper, the environment around Fe atoms changes from a BCC to an FCC structure. As a matter of fact, it creates a mixture of FCC phase with high $\mathrm{Cu}$ concentration beside another FCC phase with high $\mathrm{Fe}$ concentration, rather than an uniform solid solution. The atomic environment around $\mathrm{Fe}$ and $\mathrm{Cu}$ atoms is also investigated using $\mathrm{X}$-ray absorption near edge structure (XANES) technique [35]. It is expressed that in a powder blend with $40 \% \mathrm{Fe}$, the probability of the presence of a homogenous FCC structure is more than a mixture of FCC and BCC clusters, while for $60 \%$ Fe it is more likely to have a mixture.

Mossbauer spectroscopy is another way that is applied to study the environment around $\mathrm{Fe}$ and $\mathrm{Cu}$ atoms. It is mentioned in [55] that true alloying between $\mathrm{Cu}$ and Fe can be confirmed by means of Mossbauer spectroscopy, while there are dissimilar reports in some other published papers. The presence of $\gamma$-Fe with an FCC structure that could not be detected via XRD analysis has been reported [42]. It is noted in [24] that the FCC and BCC iron are both present while the resultant solid solution is said to be homogenous.

Considering the above-mentioned disagreement, in this work the amount of the FCC and BCC phases is determined using high quality XRD profiles and Rietveld analysis. The results can be seen in Fig. 6. It is obvious that the BCC phase does not diminish completely, even after $96 \mathrm{~h}$ of milling. Although the starting percentage of the FCC and BCC phases are from a wide region, by increasing milling time the final amounts converge to about $85 \%$ of the FCC and $15 \%$ of the BCC phases.

To the best of our knowledge, $200 \mathrm{~h}$ is the maximum time of milling in this system; the XRD profiles are printed in the literature [56]. In that time, still the (110) peak of the BCC phase can be 


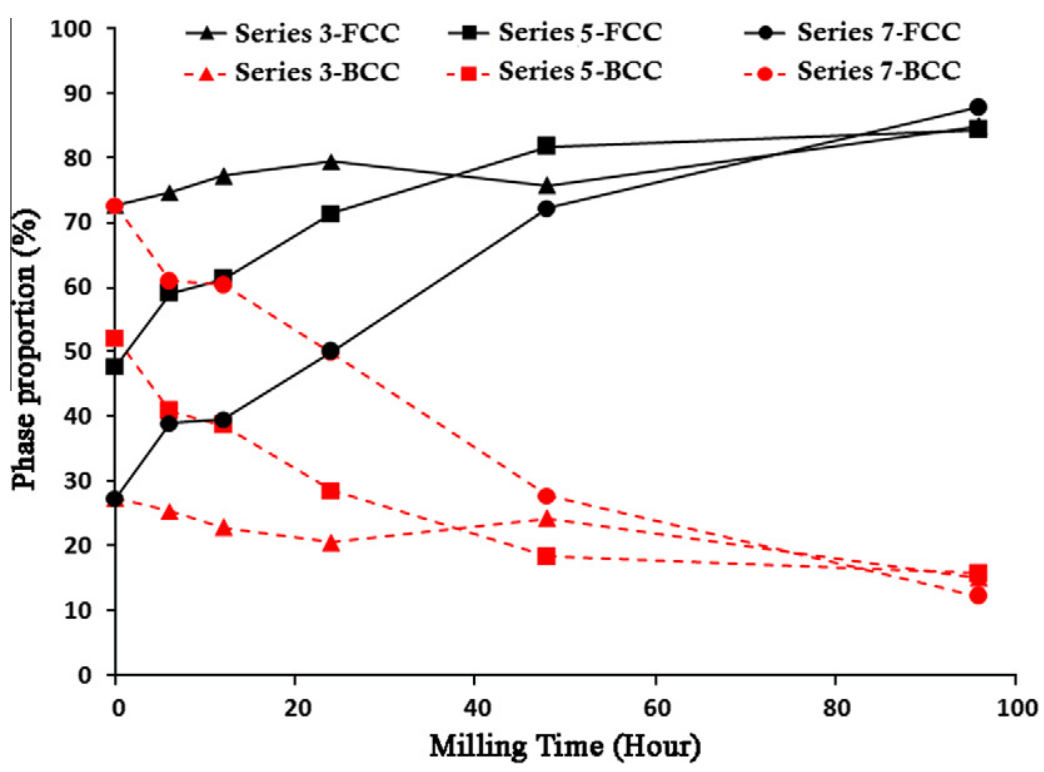

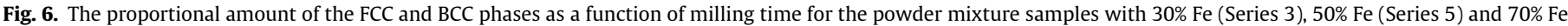
(Series 7).

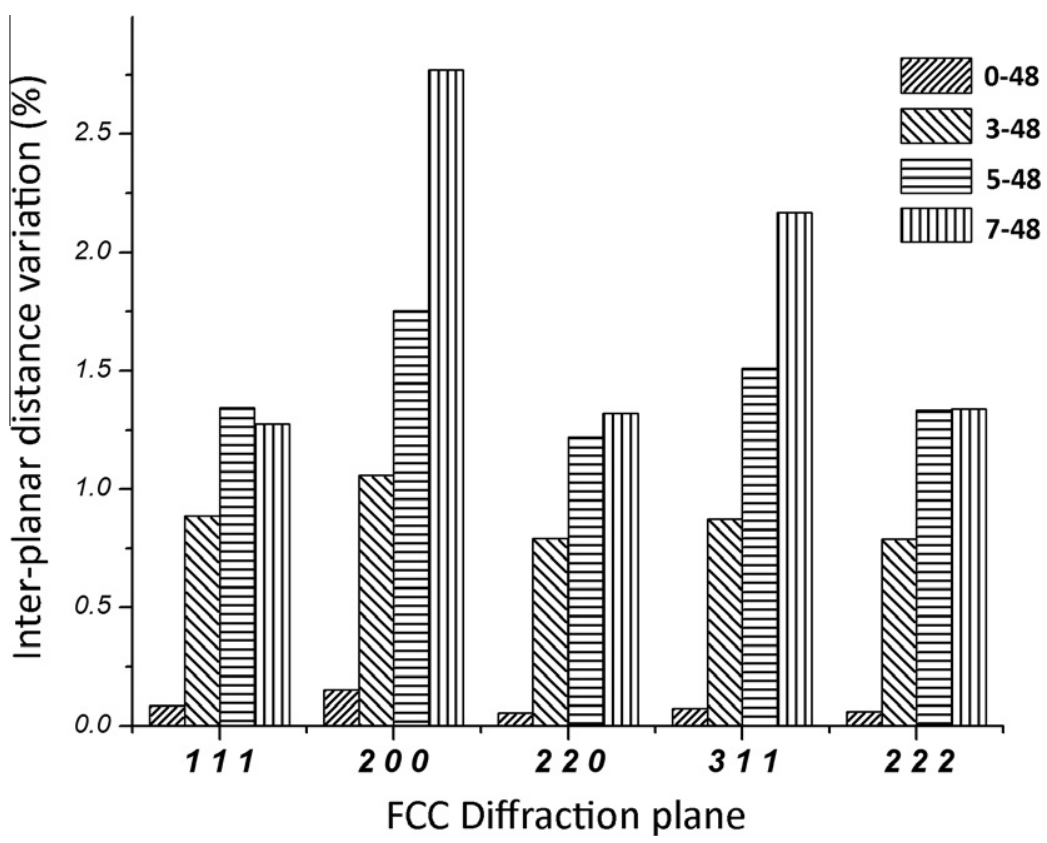

Fig. 7. Variations of the distance between diffraction planes of the FCC phase in pure copper and samples with $30 \%$ to $70 \%$ of iron, all milled for $48 \mathrm{~h}$.

Table 2

Variations of interplanar distances for $48 \mathrm{~h}$ milled samples. The data are normalized to the variation in the $\langle 111$ direction for each sample.

\begin{tabular}{lllll}
\hline Sample & $200 / 111$ & $220 / 111$ & $311 / 111$ & $222 / 111$ \\
\hline $0-48$ & 1.809 & 0.666 & 0.887 & 0.736 \\
$3-48$ & 1.195 & 0.893 & 0.988 & 0.891 \\
$5-48$ & 1.307 & 0.909 & 1.125 & 0.994 \\
$7-48$ & 2.173 & 1.037 & 1.700 & 1.049 \\
\hline
\end{tabular}

detected as an asymmetry in the (111) peak of FCC. Therefore, it was concluded that the super saturated FCC and BCC phases would be homogeneous to an atomic level solution, while the overall powder does not consist of a single homogeneous phase, due to the residual nano crystallites with BCC structure in all samples. To obtain a mixture of about $85 \%$ FCC and $15 \%$ BCC phases as the semi-equilibrium state in the whole mentioned range of compositions, it will be necessary to have variable solubility limits of Fe and $\mathrm{Cu}$. To fulfill the lever rule for the FCC and BCC phases, the solubility limit of $\mathrm{Fe}$ in $\mathrm{Cu}$ should be higher for the higher $\mathrm{Fe}$ contents and vice versa.

\subsubsection{Anisotropy of deformation}

The breadth of the peaks is increased up to $48 \mathrm{~h}$ of milling, which is due to the convolution of the effects of crystallite size, strain and lattice defects. However, the intensity of deformation is not isotropic through different lattice directions. Fig. 7 shows the variation of interplanar distance in the direction perpendicular 


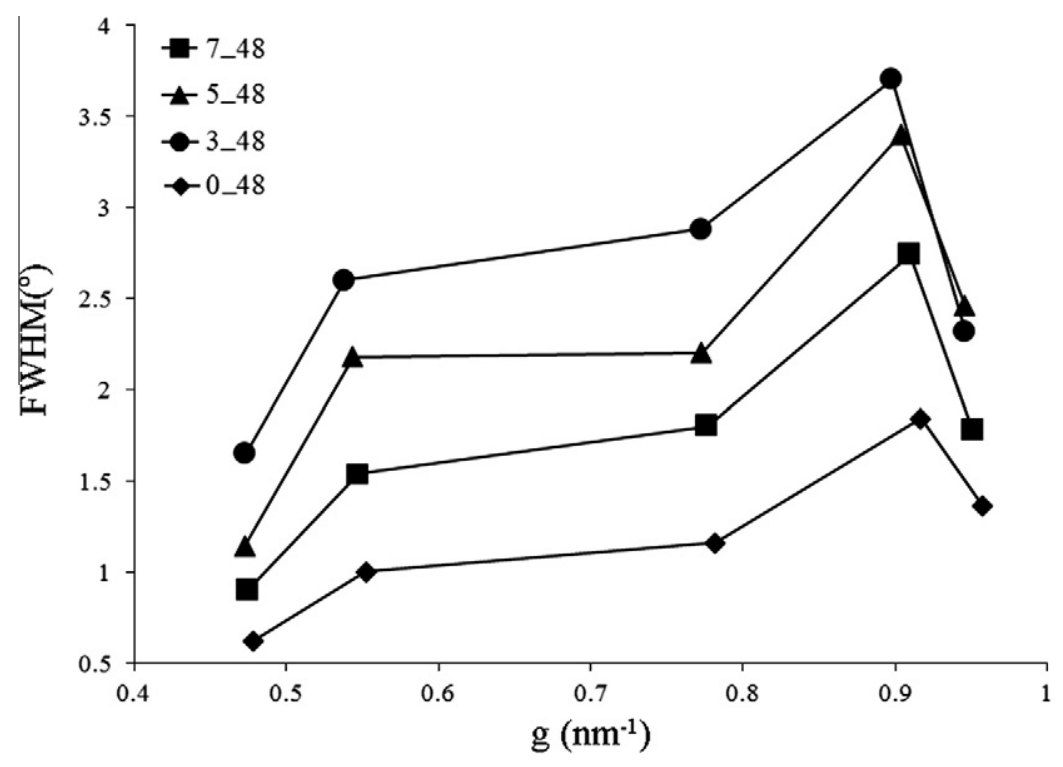

Fig. 8. Variations of FWHM with $g$, for samples which are milled for $48 \mathrm{~h}$.

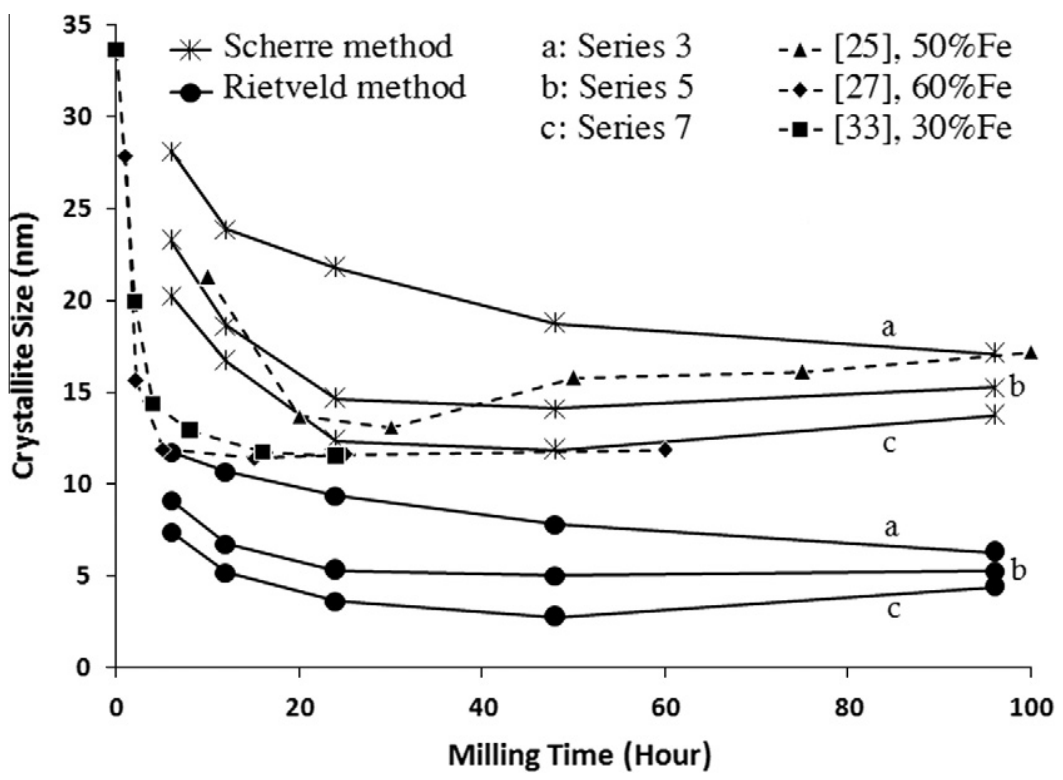

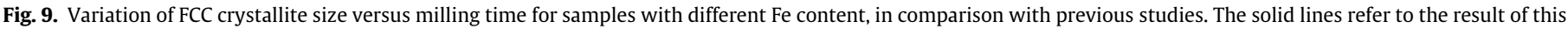
work and dash lines are related to the prior results. [25] and [27] used the Scherer method and [33] used the WH method.

to each of the diffracted planes of the FCC lattice for the samples that are milled for $48 \mathrm{~h}$. In all cases, the extension of interplanar distance in the $\langle 200\rangle$ direction is more remarkable. However, it should be noticed that this anisotropy can also be seen in the milled pure copper. As can be seen in (Table 2), the intensity of the anisotropy in $\langle 200\rangle$ and $\langle 222\rangle$ directions decrease by increment of Fe content. But the interplanar spacing in the $\langle 311\rangle$ direction shows a continuous increasing trend by the addition of super-saturated iron atoms, which can be one reason for the tendency of iron atoms to place in this direction.

A common method to separate the broadening effect due to crystallite size from strain, is the Williamson-Hall (WH) method [57]. It should be noticed that the WH method is not proper for all kinds of powders. The variations of FWHM with diffraction vector $(g)$ for five FCC peaks is shown in Fig. 8. As is seen, the FWHM is not a monotonous function of $g$, indicating the progress of the data with $g$ is strongly anisotropic, therefore the WH method cannot offer precise enough results in this case, and its results show bigger crystallites for highly deformed metallic samples [58,59].

Fig. 9 illustrates the changes in crystallite size versus milling time. The results obtained from Scherer and Rietveld method in this work are compared with some previously available results which are obtained from the Scherer and Williamson-Hall methods. The differences between the results in published studies can be related to the differences in milling conditions such as the energy of milling or usage of lubricants, but it should be noted that the method of crystallite size calculation is also effective. The Scherer equation does not separate the effects of lattice strain and crystallite size in line broadening; therefore its results will contain serious error in case of highly deformed metallic powders like products of mechanical alloying. The Rietveld method uses the intensity of all diffraction points; therefore in case of materials 

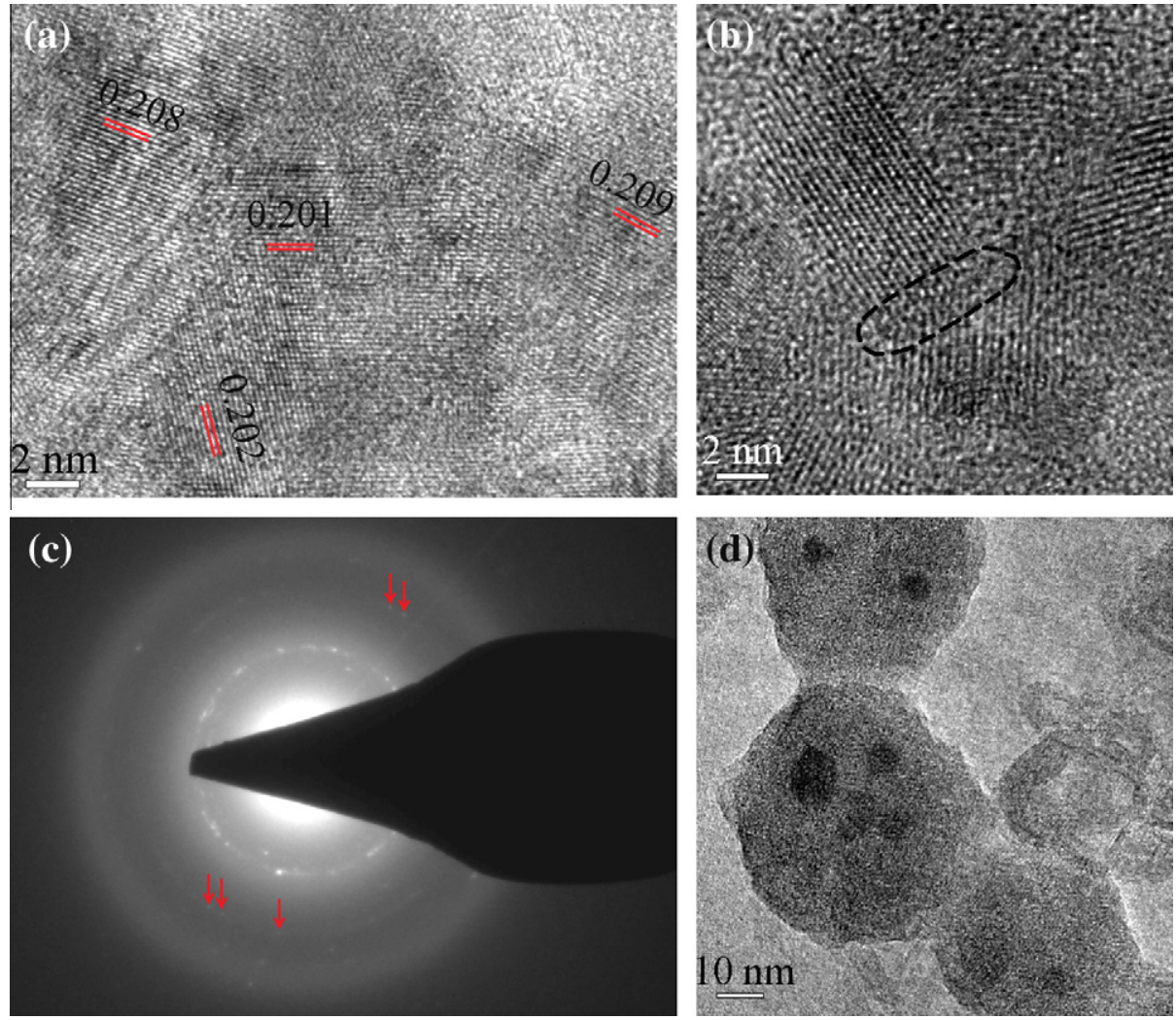

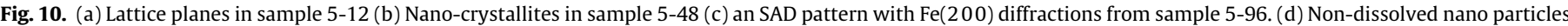
in sample 5-48.

with overlapped peaks, such as the main peaks of $\mathrm{Fe}$ and $\mathrm{Cu}$, this method has another advantage over conventional methods, like Scherer and Williamson-Hall.

De-convolution of crystallite size effect using Rietveld full profile fitting, results in somehow smaller crystallite size. On the other hand, line broadening is dissimilar for different FCC peaks. As can be seen in (Table 1), crystallites mostly have the maximum size in $\langle 111\rangle$ direction and the minimum is towards $\langle 200\rangle$. Therefore, considering a wider diffraction range which includes more peaks will result in a more accurate crystallite size in the $\mathrm{Cu}-\mathrm{Fe}$ system.

Anomalous peak broadening in FCC metals can be due to formation of stacking faults in (111) plane [60]. There is, however, a similarity between directions with high interplanar distance increment and directions which display smaller crystallite sizes in the milled powder.

As can be predicted, continuation of milling results in reaching a steady state level of crystallite size. However, in series 7 there is a slight increase in the size of FCC crystallites in period of 48-96 h. This can support the idea of re-crystallization of amorphous phase in samples with $70 \%$ Fe content.

As the Fe proportion increased from $30 \%$ to $70 \%$, the FCC crystallites became smaller. This is in agreement with previous results [27]. It is also considerable that with the progress of milling, the BCC crystallite size becomes smaller than that of FCC. This circumstance is the same as in the literature $[26,43]$. The BCC crystallite size is not reported here for samples which are subjected to 48 and $96 \mathrm{~h}$ of milling, due to inadequate quality of fits to small and broadened BCC peaks. Moreover, It is mentioned in the literature that the Fe crystallite size in the BCC range of compositions reduces by an increase in Cu proportion as well [33]. This can be due to reduction of ductility because of solid solution hardening in a super saturated alloy. However, it is reported that in the range of
$4 \leqslant \mathrm{Cu} \leqslant 12$ percent, the crystallite size is independent of composition [36].

\subsubsection{TEM observations}

In order to achieve a better understanding about the formation of the non-equilibrium phases, samples 5-12, 5-48 and 5-96 were

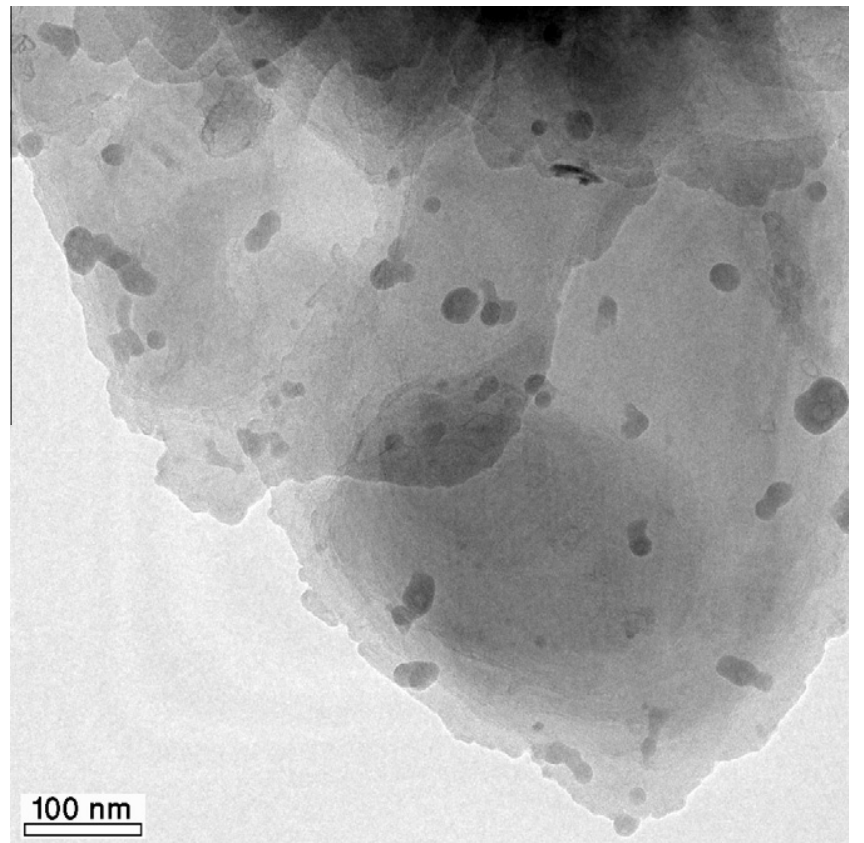

Fig. 11. Non-dissolved particles inside two grains of sample 5-48 

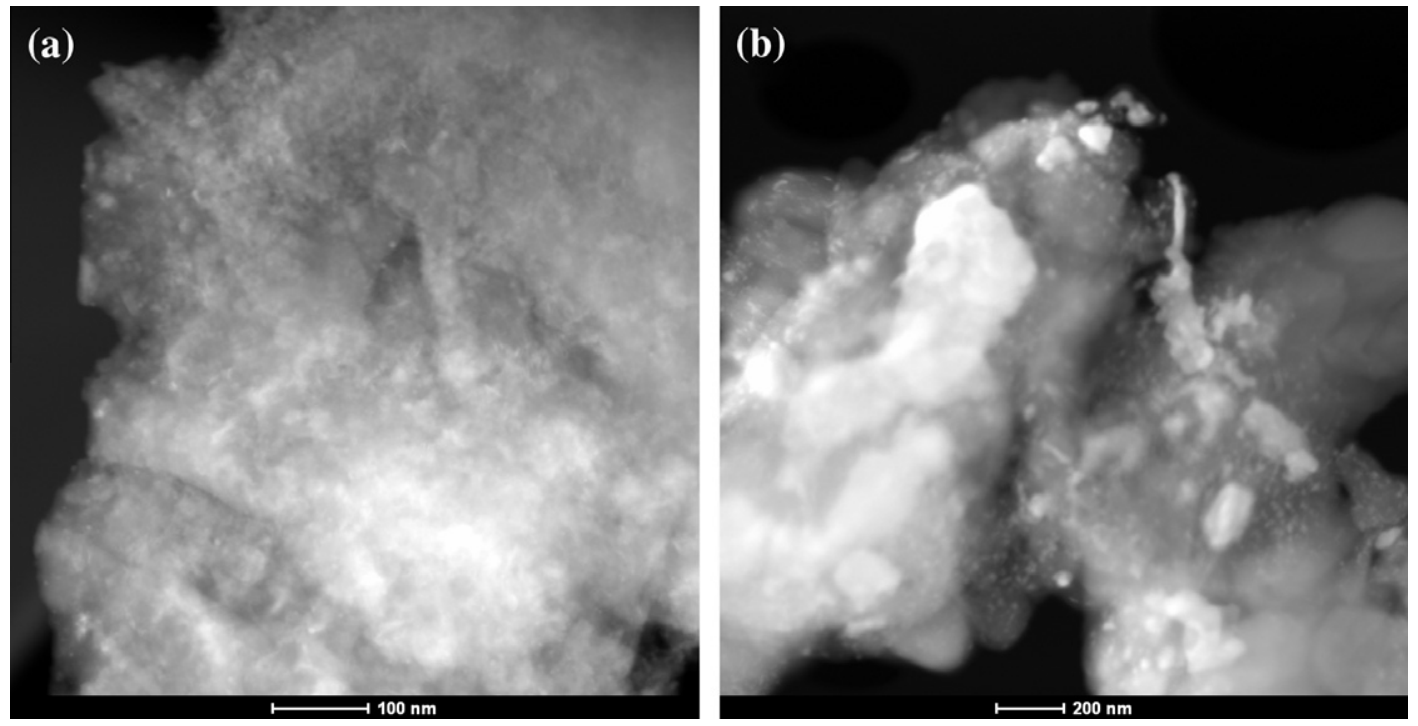

Fig. 12. HAADF images showing Z-contrast in samples (a) 5-48 and (b) 5-96.

investigated using high resolution TEM. The mixed up crystallites of $\mathrm{Fe}$ and $\mathrm{Cu}$ can be detected in all specimens, as illustrated in Fig. 10(a) for the sample milled for $12 \mathrm{~h}$. The interplanar distances in this Figure are in close proximity to $\mathrm{Cu}(111)$ and $\mathrm{Fe}(110)$. The minor inaccuracy can be due to slight errors in calculation or scale bars of the images.

As an example of lattice defects, two crystallites with mirror symmetry can be seen in Fig. 10(b), which can be an indication of a twin boundary in the FCC lattice. Around the crystallite at the top of the image, there is no apparent order between visible dots. This pattern can implicate the formation of amorphous regions, as mentioned in [28].

Fig. 10(c) shows a SAD pattern for crystallites of sample 5-96. The points which are marked with arrows are related to the $\mathrm{Fe}(200)$ plane. Therefore, the BCC Fe crystallites are still present after $96 \mathrm{~h}$ of milling. Moreover, dispersed equiaxed nanocrystallites that are not dissolved in the background phase can be obviously seen in Fig. 10(d) and Fig. 11. This is in good agreement with the XRD results on formation of a dual phase structure. It has been shown by STEM Z-contrast imaging that an uniform structure is formed up to $25 \%$ Fe content [51] Now, it can be seen that a complete single phase solid solution could not form in higher concentrations.

Z-contrast imaging is also utilized in order to better investigate the dispersion of solute and solvent material, and the presence of clusters with non-uniform composition. High angle annular dark field (HAADF) STEM is a powerful method for such purposes. Fig. 12 shows two HAADF images of samples 5-48 and 5-96. The element with lower atomic number (iron) can be identified by brighter regions. Fig. 12(a) shows a quite uniform dispersion. But this does not represent the formation of a single phase solid solution. The presence of bright particles is obvious in Fig. 12(b). Smaller white spots are also visible inside gray zones. These prove the formation of a dual phase structure, alongside with a quite uniform solid solution inside each phase.

\section{Conclusion}

The development of non-equilibrium solid solution by mechanical alloying of $\mathrm{Cu}-\mathrm{Fe}$ powder mixture has been investigated. The deformation in the super-saturated FCC structure is not isotropic in various directions. The distances between lattice planes have a greater increase towards $\langle 200\rangle$ and $\langle 311\rangle$ directions. The Rietveld full profile analysis shows a more reliable crystallite size than the Scherer and Williamson-Hall methods for the resulting powder and the obtained crystallites sizes by Rietveld refinement are smaller. The anisotropic behavior can also be detectable in the crystallite size variation. Therefore, it is important to mention that the reported information may exhibit an average number.

FCC phase is the dominant structure in our conditions of milling for up to $70 \mathrm{wt} . \%$ of iron, but BCC phase with crystallite size less than $10 \mathrm{~nm}$ still exists. Analysis of XRD profiles confirms the formation of a dual phase mixture with about $85 \%$ of FCC and $15 \%$ of BCC phase in all the experimented compositions. Existence of a dual phase structure is also confirmed by the aid of high resolution TEM observations. HAADF Z-contrast imaging verifies the presence of Fe rich regions inside the super saturated $\mathrm{Cu}$ rich solid solution. While the resultant powder is not a single phase solution, each of the FCC and BCC phases are homogenous solid solutions.

\section{References}

[1] S. Mula, H. Bahmanpour, S. Mal, P.C. Kang, M. Atwater, W. Jian, R.O. Scattergood, C.C. Koch, Mater. Sci. Eng. A 539 (2012) 330-336.

[2] E. Botcharova, J. Freudenberger, L. Schultz, J. Alloys Comp. 365 (2004) 157-163.

[3] X. Cui, L. Wang, M. Qi, J. Mater. Sci. Technol. 17 (2001) S89-S92.

[4] C. Aguilar, J. Marín, S. Ordóñez, D. Celentano, F. Castro, V. Martínez, Revista de Metalurgia 42 (2006) 334-344.

[5] P.A. Rojas, A. Peñaloza, C.H. Wörner, R. Fernández, A. Zúñiga, J. Alloys Comp. 425 (2006) 334-338.

[6] C. Aguilar, F. Castro, V. Martínez, D. Guzmán, F. de las Cuevas, L. Lozada, N. Vielma, Mater. Sci. Eng. A 548 (2012) 189-194.

[7] V.D.P. Martínez, C. Aguilar, J. Marín, S. Ordoñez, F. Castro, Mater. Lett. 61 (2007) 929-933.

[8] K. Sakurai, C.H. Lee, N. Kuroda, T. Fukunaga, U. Mizutani, J. Appl. Phys. 75 (1994) 7752-7755

[9] S.N. Alam, Mater. Sci. Eng. A 433 (2006) 161-168.

[10] M.H. Maneshian, A. Simchi, Z.R. Hesabi, Mater. Sci. Eng. A 445-446 (2007) 8693.

[11] D.Y. Ying, D.L. Zhang, J. Alloys Comp. 311 (2000) 275-282.

[12] C. Gente, M. Oehring, R. Bormann, Phys. Rev. B 48 (1993) 13244-13252.

[13] G. García-Pacheco, G. Cabañas, C.S. Santiago López-Cajún, A. Herrera, V. Castaño, Mater. Res. Innovat. 3 (2000) 332-339.

[14] M. Azimi, G.H. Akbari, J. Alloys Comp. 509 (2011) 27-32.

[15] X.R. Liu, Y.B. Liu, Z.Y. Cao, X. Ran, X.Y. Guo, Cailiao Rechuli Xuebao Trans. Mater. Heat Treat. 27 (2006) 31-33.

[16] N.S. Cohen, E. Ahlswede, J.D. Wicks, Q.A. Pankhurst, J. Phys.: Condens. Matter 9 (1997) 3259-3276.

[17] M. López, V. Núñez, R. Koduri, M.E. Gómez, J. Jiménez, D. Reyes, Powder Metall. 55 (2012) 148-153.

[18] M.R. Rezvani, A. Shokuhfar, Mater. Sci. Eng. A 532 (2012) 282-286.

[19] A.I. Pashkov, S.P. Gerasimov, Russ. J. Non-Ferr. Met. 50 (2009) 610-611. 
388

M. Mojtahedi et al./Journal of Alloys and Compounds 550 (2013) 380-388

[20] Y.L. Chen, Y.H. Hu, C.W. Tsai, C.A. Hsieh, S.W. Kao, J.W. Yeh, T.S. Chin, S.K. Chen, J. Alloys Comp. 477 (2009) 696-705.

[21] J. Bhatt, G.K. Dey, B.S. Murty, Metall. Mater. Trans. A: Phys. Metall. Mater. Sci. 39 (2008) 1543-1551.

[22] P.J. Schilling, J.H. He, J. Cheng, E. Ma, Appl. Phys. Lett. 68 (1996) 767-769.

[23] J.Z. Jiang, F.T. Chen, J. Phys.: Condens. Matter 6 (1994) L343-L348.

[24] J.Z. Jiang, C. Gente, R. Bormann, Mater. Sci. Eng. A 242 (1998) 268-277.

[25] J.Z. Jiang, U. Gonser, C. Gente, R. Bormann, Appl. Phys. Lett. 63 (1993) 27682770.

[26] J.Z. Jiang, J.S. Olsen, L. Gerward, S. Mørup, Nanostruct. Mater. 12 (1999) 847850.

[27] J.Y. Huang, A.Q. He, Y.K. Wu, Nanostruct. Mater. 4 (1994) 1-10.

[28] J.Y. Huang, A.Q. He, Y.K. Wu, H.Q. Ye, D.X. Li, J. Mater. Sci. 31 (1996) 41654169.

[29] X. Huang, T. Mashimo, J. Alloys Comp. 288 (1999) 299-305.

[30] E. Gaffet, M. Harmelin, F. Faudot, J. Alloys Comp. 194 (1993) 23-30.

[31] E. Ma, M. Atzmon, F.E. Pinkerton, J. Appl. Phys. 74 (1993) 955-962.

[32] J. Eckert, J.C. Holzer, W.L. Johnson, J. Appl. Phys. 73 (1993) 131-141.

[33] J. Eckert, J.C. Holzer, C.E. Krill, W.L. Johnson, J. Appl. Phys. 73 (1993) 27942802.

[34] S. Wei, W. Yan, Y. Li, W. Liu, J. Fan, X. Zhang, Phys. B: Condens. Matter 305 (2001) 135-142.

[35] A.N. Kravtsova, G.E. Yalovega, A.V. Soldatov, W.S. Yan, S.Q. Wei, J. Alloys Comp. 469 (2009) 42-49.

[36] R.A. Dunlap, D.A. Eelman, G.R. Mackay, J. Mater. Sci. Lett. 17 (1998) 437-439.

[37] C.G. Wille, T. Al-Kassab, R. Kirchheim, Ultramicroscopy 111 (2011) 730-737.

[38] A. Yousif, K. Bouziane, M.E. Elzain, X. Ren, F.J. Berry, H.M. Widatallah, A. Al Rawas, A. Gismelseed, I.A. Al-Omari, Hyperfine Interact. 156-157 (2004) 213221.

[39] Y. Yang, X. Ma, Y. Dong, Acta Metall. Sinica-Chin. Ed. 28 (1992) 403.
[40] F. Faudot, E. Gaffet, M. Harmelin, J. Mater. Sci. 28 (1993) 2669-2676.

[41] V.V. Cherdyntsev, S.D. Kaloshkin, Phys. Met. Metall. 109 (2010) 492-504.

[42] P.P. Macrí, P. Rose, R. Frattini, S. Enzo, G. Principi, W.X. Hu, N. Cowlam, J. Appl. Phys. 76 (1994) 4061-4067.

[43] L.B. Hong, B. Fultz, Acta Mater. 46 (1998) 2937-2946.

[44] P. Gorria, D. Martínez-Blanco, J.A. Blanco, M.J. Pérez, M.A. González, J. Campo, Phys. B 384 (2006) 336-340.

[45] G. Caglioti, A. Paoletti, F.P. Ricci, Nucl. Instrum. 3 (1958) 223-228.

[46] J.I. Langford, A.J.C. Wilson, J. Appl. Crystallogr. 11 (1978) 102-113.

[47] H.M. Rietveld, Acta Crystallogr. A 22 (1967) 151-152.

[48] Y. Waseda, E. Matsubara, K. Shinoda, X-ray Diffraction Crystallography, Introduction, Examples and Solved Problems, Springer-Verlag, Berlin, Heidelberg, 2011.

[49] M. Oehring, R. Bormann, Mater. Sci. Eng. A 134 (1991) 1330-1333.

[50] H.G. Tang, X.F. Ma, W. Zhao, X.W. Yan, R.J. Hong, J. Alloys Comp. 347 (2002) 228-230.

[51] J.C. Crivello, T. Nobuki, T. Kuji, Mater. Trans. 49 (2008) 527-531.

[52] T.G. Nieh, J. Wadsworth, Scr. Metall. Mater. 25 (1991) 955-958.

[53] C. Suryanarayana, Mechanical Alloying and Milling, Marcel Dekker, New York, 2004.

[54] E. Ma, J.H. He, P.J. Schilling, Phys. Rev. B: Condens Matter Mater. Phys. 55 (1997) 5542-5545.

[55] N.S. Cohen, M. Odlyha, D.H. Ucko, Q.A. Pankhurst, J. Therm. Anal. Calorim. 56 (1999) 239-245.

[56] A.R. Yavari, P.J. Desré, T. Benameur, Phys. Rev. Lett. 68 (1992) 2235-2238.

[57] G.K. Williamson, W.H. Hall, Acta Metall. 1 (1953) 22-31.

[58] T. Ungár, Á. Révész, A. Borbély, J. Appl. Crystallogr. 31 (1998) 554-558.

[59] I.C. Dragomir, T. Ungár, J. Appl. Crystallogr. 35 (2002) 556-564.

[60] V.I. Fadeeva, A.V. Leonov, E. Szewczak, H. Matyja, Mater. Sci. Eng. A 242 (1998) 230-234. 